\title{
Main results of the second AIRP international radon-in-field intercomparison for passive measurement devices
}

\author{
F. Berlier ${ }^{\mathrm{a}}$, F. Cardellini ${ }^{\mathrm{b}}$, E. Chiaberto ${ }^{\mathrm{c}}$, L. Garlati $^{\mathrm{d}}$, D. Giuffrida ${ }^{\mathrm{e}}$, M. Faure Ragani ${ }^{\mathrm{a}}$, \\ F. Leonardi ${ }^{f, *}$, M. Magnoni ${ }^{c}$, G. Minchillo ${ }^{g}$, A. Prandstatter ${ }^{c}$, E. Serena ${ }^{c}$, R. Trevisi ${ }^{f}$, R. Tripodi ${ }^{c}$, \\ S. Verdelocco ${ }^{\mathrm{h}}$, M. Veschetti ${ }^{\mathrm{f}}$ \\ a ARPA Valle d'Aosta, Italy \\ ${ }^{\mathrm{b}}$ ENEA/INMRI, Rome, Italy \\ ${ }^{\mathrm{c}}$ ARPA Piemonte, Ivrea, Italy \\ d Politecnico di Milano, Milano, Italy \\ ${ }^{\mathrm{e}}$ FANR, Abu Dhabi, United Arab Emirates \\ ${ }^{\mathrm{f}}$ INAIL - Research Sector/DiMEILA, Monteporzio Catone, Italy \\ ${ }^{\mathrm{g}} \mathrm{JRC}$, Ispra, Italy \\ ${ }^{\text {h } C E R A P ~ S A, ~ C h e r b o u r g ~ O c t e v i l l e, ~ F r a n c e ~}$
}

\section{Introduction}

According the ISO/IEC 17025:2017 standard (ISO, 2017), the periodical participation in inter-laboratory comparisons (as Proficiency Test) is a tool laboratories may use to assess or to monitor their own performances. Typically, radon intercomparison exercises are carried out in radon reference chambers (STAR) under stable and controlled environmental conditions in term of radon levels, temperature, humidity and atmospheric pressure (IEC 61577-4, 2009).

Nevertheless, radon laboratories are interested in testing their monitoring systems by in-field exercises, taking place in less controlled and much more variable real conditions, similar to the ones in which radon passive devices are normally exposed. Following the interesting experience done in 2012 in Spain (Gutiérrez-Villanueva et al., 2012), the first edition of the "International radon in-field intercomparison for passive measurement devices" was held in 2014. The main scope was to test passive radon devices exposed in "extreme" environmental conditions (average radon activity concentration above $10,000 \mathrm{~Bq} / \mathrm{m}^{3}$, huge fluctuations of radon concentration values and relative humidity near to $95 \%$ ). More details are available elsewhere (Cardellini et al., 2016a, 2016b).

In the second "International radon in-field intercomparison for passive measurement devices: dwellings and workplaces" the attention was focused on different issues potentially affecting the quality of radon concentration measurements in real situations. In particular, the effect of long time sampling at low and high radon levels (fading) (Caresana et al., 2010; Venoso et al., 2016) and the effect of the simultaneous presence of radon and thoron (Sumesh et al., 2013; Tokonami et al., 2008). In order to provide reliable reference values of the activity radon concentration, before the intercomparison started, particular attention was paid to metrological issues as the determination of the intrinsic background of radon active monitors, to their calibration and to the evaluation of the influence of thoron in radon active measurements.

Participants were invited to deliver three groups of six radon passive devices for the three different tests. Two groups were exposed in workplaces (an office and a storage room) for a 5-months long period at typical indoor radon activity concentrations to evaluate the effect of fading. The third test was shorter but in a "complex situation", such as a cellar characterized by the simultaneous presence of high levels of radon and thoron, to evaluate the possible influence of thoron on the response of radon passive devices.

Participants had to provide results as radon exposure of each passive device, as in terms of radon activity concentration of each group, in order to gather information on laboratories procedures of data management, e.g. in case of outliers, and on the evaluation of transits.

It is worth to note that, as for the first edition, to evaluate the laboratory performances any ranking criteria was not used, mostly due to the great difficulty and complexity of in-field intercomparisons. It was preferred to simply calculate and discuss a number of statistical parameters as indicators of the performance relevant not only to the participant but to the measurement system as well. In the present paper, a synthesis of main results is given.

\section{Material and methods}

\subsection{Metrological aspects}

In order to provide reliable reference values, many metrological activities were carried out. They consisted in calibration of a subset of the radon active monitors at the Italian National Metrological Institute

\footnotetext{
* Corresponding author.

E-mail address: f.leonardi@inail.it (F. Leonardi).
} 
Table 1

Overview of active monitors used during the intercomparison activity.

\begin{tabular}{|c|c|c|}
\hline Radionuclide & Active monitor & Detection principle \\
\hline Radon & $\begin{array}{l}\text { n. } 5 \text { Alphaguard } \\
\text { n. } 10 \text { RADIM 5B } \\
\text { n. } 4 \text { Lucas Cells } \\
\text { monitors }\end{array}$ & $\begin{array}{l}\text { pulse-counting ionization } \\
\text { chamber } \\
\text { semiconductor detector } \\
\text { alpha scintillation chamber }\end{array}$ \\
\hline Radon/Thoron & $\begin{array}{l}\text { n.1 Thoron Scout } \\
\text { (TS) } \\
\text { n. } 1 \text { NG Alphaguard } \\
\text { n.1 EQF } 3220\end{array}$ & $\begin{array}{l}\text { semiconductor detector } \\
\text { pulse-counting ionization } \\
\text { chamber } \\
\text { semiconductor detector }\end{array}$ \\
\hline $\begin{array}{l}\text { Airborne Radon and } \\
\text { Thoron progeny }\end{array}$ & n.1 EQF 3220 & semiconductor detector \\
\hline
\end{tabular}

a NG AlphaGuard = New Generation AlphaGuard.

(ENEA-INMRI), estimation of the calibration factors (CF) and of the intrinsic background of all the available monitors, and the tests in mixed radon/thoron atmosphere with the aim to identify instruments with the best stability performances. Moreover, the estimation of gamma dose rate of the three selected sites by using TLD_100 was done. Hereby, some details are given.

A total number of 22 different active monitors were used during the intercomparison activity: 19 radon gas monitors based on different detection principles (ionization chambers, semiconductor detectors and alpha scintillation chambers), 3 radon-thoron monitors and 1 radon progeny monitor. Table 1 shows the list of instruments.

A subset of the instruments was calibrated by using the Radon Reference Measuring System (ENEA-INMRI RRMS) and the Thoron Reference Measuring System (ENEA-INMRI TRMS) at ENEA-INMRI facility, in order to provide the metrological traceability. Moreover, the instruments were tested in a radon/thoron mixed atmosphere (see par. 2.1.2).

The Radon Reference Measuring System (ENEA-INMRI RRMS) consists of an aluminium flask with a volume of $111.77 \mathrm{~L}$, one radon monitor (a scintillation cell) and a group of radon sources (see Fig. 1). All the elements of the system are connected in a closed circuit in which the air can circulate by means of a micropump placed in the aluminium flask. The circuit is equipped with a flow-meter, a manometer and a hygrometer. Further details about the ENEA-INMRI RRMS are available in (Cardellini et al., 2016b).

Afterward, the calibration factors ( $\mathrm{CFs}$ ) of all the other monitors were obtained by exposures at different radon atmospheres $(38,000 \mathrm{~Bq} /$ $\mathrm{m}^{3}, 14,000 \mathrm{~Bq} / \mathrm{m}^{3}$ and $8000 \mathrm{~Bq} / \mathrm{m}^{3}$ ) in CeSNEF (Politecnico of Milan) and ARPA Piemonte radon chambers, using monitors previously calibrated in ENEA-INMRI as secondary standards.

The accurate determination of the intrinsic background of instruments (also referred to as "blank") is another important issue for accurate and reliable measurements, in particular in case of low radon concentrations (order of tens of $\mathrm{Bq} / \mathrm{m}^{3}$ ). Tests for the blank indication (Cardellini et al., 2013) were carried out at ENEA-INMRI and at Politecnico of Milan in radon-free aged air and at ARPA Piemonte in $\mathrm{N}_{2}$ atmosphere. For the scope of the in-field intercomparison, the reference radon value was obtained by using only active monitors with best stability performances, in terms of low background and calibration factor. Moreover, passive radon dosimeters (ANPA holder (Tommasino, 2001) and CR39 as detector) were placed to assess the spatial distribution of radon in each site.

Finally, to evaluate correctly the electret response (Kotrappa et al., 1988) the gamma dose rate was assessed by thermo-luminescent dosimeters (TLD-100, Harshaw Chemical Co., Cleveland, OH), with chemical formula LiF:Mg,Ti, as a powder encapsulated in glass, in chip format with dimensions of $3.2 \times 3.2 \times 0.9 \mathrm{~mm}^{3}$. TLD-100 dosimeters were calibrated at LAT Laboratory n. 104 - Politecnico of Milan: the calibration factor was evaluated by exposure to a radiation field produced by a ${ }^{137} \mathrm{Cs}$ source $(7 \mathrm{GBq}$ ) at a distance of $1 \mathrm{~m}$ for $40 \mathrm{~h}$. Afterward, TLDs were collected and read using a Harshaw Model 2000-C TL detector equipped with a system for the treatment and signal amplification (Model, 2000-B Automatic Integrative Picoammeter) in the temperature range $150-250^{\circ} \mathrm{C}$.

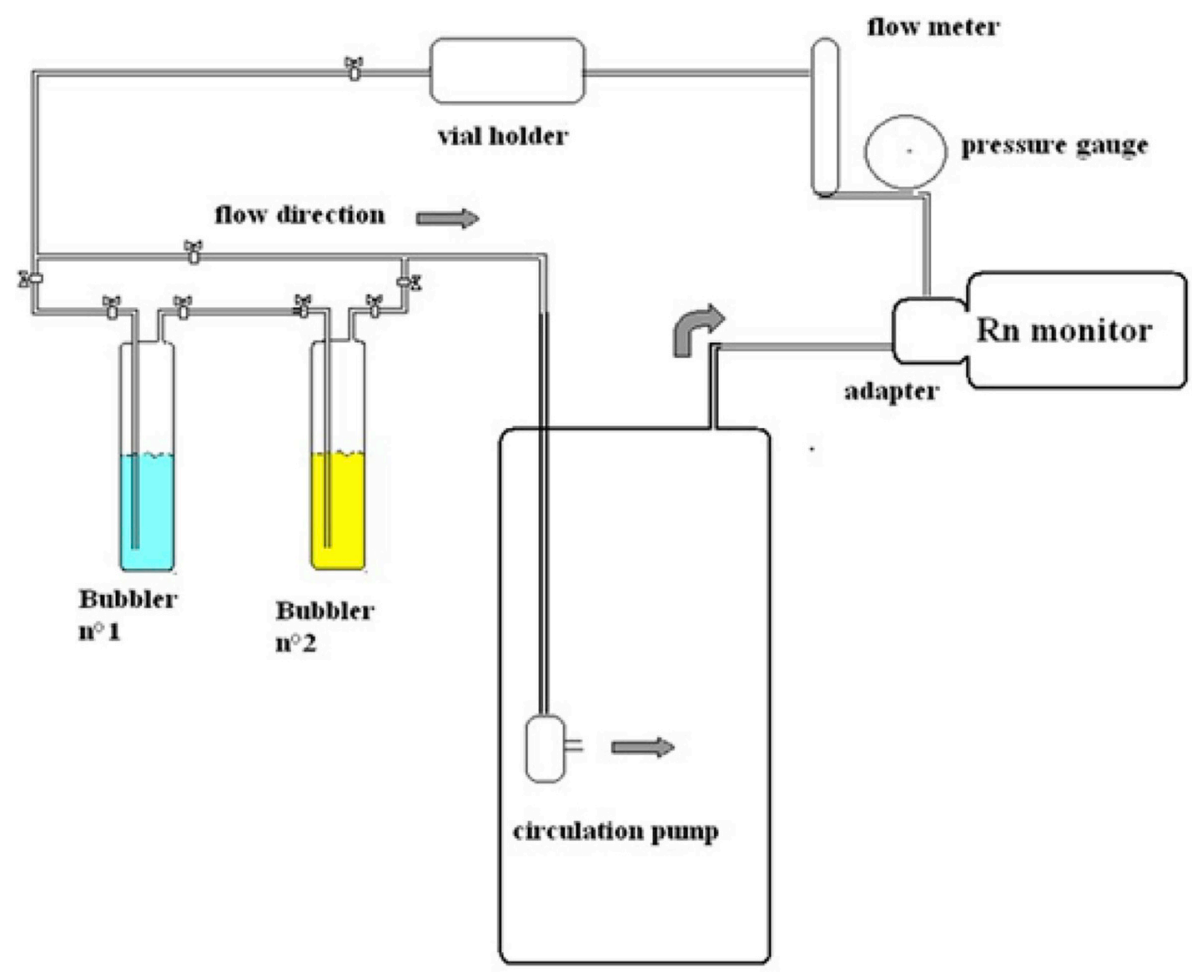

Fig. 1. ENEA-INMRI Radon Reference Measuring System (ENEA-INMRI RRMS): scheme of the primary circuit for radon measurements in air. 


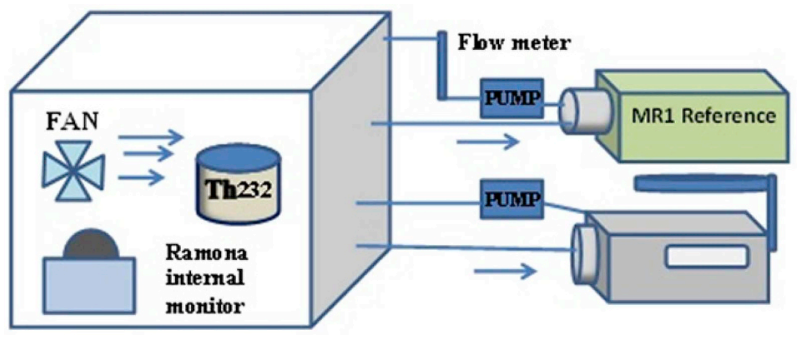

Fig. 2. ENEA-INMRI TRMS: scheme of experimental setup for ${ }^{220} \mathrm{Rn}$ measurements.

\subsubsection{The ENEA-INMRI TRMS}

A scheme of experimental setup of the ENEA-INMRI TRMS is in Fig. 2. A thoron chamber (volume $=220 \mathrm{~L}$ ) contains a Thorium-232 source (with a nominal activity of $37 \mathrm{kBq}$ ) for the ${ }^{220} \mathrm{Rn}$ production, a fan and an internal active monitor, based on electrostatic collection cell and alpha spectrometry (RaMonA-RAdon MONitoring and Acquisition), designed by INFN and the Physics Dep of the University of Naples "Federico II", Italy (Roca et al., 2004). The chamber is connected by a closed loop with a reference monitor, based on a Lucas scintillation cell (MR1 Tesys, MI.am, Italy) and eventually to a further monitor during calibrations. The internal active monitor, thanks to its own alpha spectrometry, is able to evaluate the eventual presence of ${ }^{222} \mathrm{Rn}$.

\subsubsection{Tests in mixed radon/thoron atmosphere}

At ENEA-INMRI a dedicated facility was set up in order to evaluate the interference of ${ }^{220} \mathrm{Rn}$ on radon measurements (Ishikawa, 2004; Kochowska et al., 2009; Michielsen and Bondiguel, 2015; Sumesh et al., 2013). As shown in Fig. 3, it consists in $1 \mathrm{~m}^{3}$ thoron/radon chamber, with ${ }^{220} \mathrm{Rn}$ source and a fan on the lower grid directing the thoron-rich airflow toward the bottom of the chamber. On the upper grid, one or two active monitors were placed. A known ${ }^{222} \mathrm{Rn}$ activity is introduced into the chamber from a flow-through type radon source. In this configuration, a thoron concentration of $\approx 8000 \mathrm{~Bq} / \mathrm{m}^{3}$ is constantly present into the chamber, while radon gas enters the chamber after about $21 \mathrm{~h}$ from the beginning of test.

\subsection{Participants}

In the second "International radon in-field intercomparison for passive measurement devices", 49 laboratories from 15 Countries subscribed the participation: 48 of them provided results. Participants delivered a set of 18 radon passive devices in order to have three groups of six devices (one for each test). Each group was further split: 3 devices were exposed during the test and 3 were stored in a radon proof bag and used as transits.

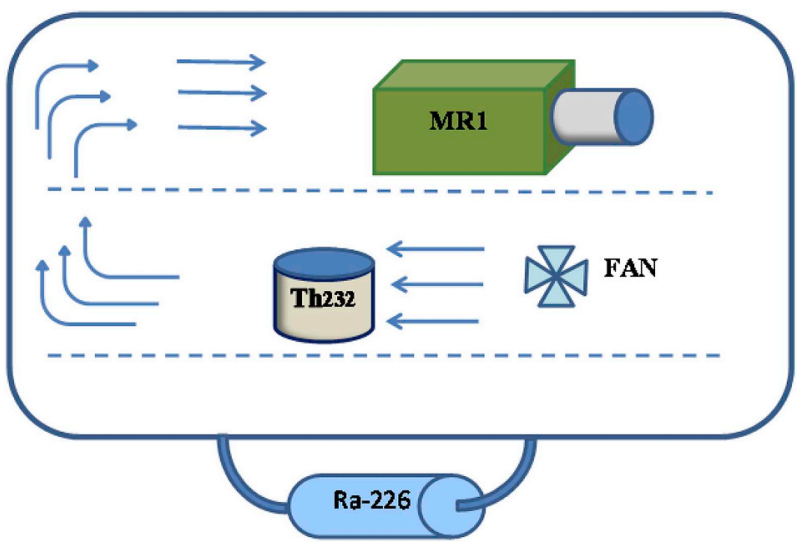

Fig. 3. Scheme of experimental setup for test in mixed Radon-Thoron atmospheres in $1 \mathrm{~m}^{3}$ thoron chamber.
Some participants delivered more than one set: 12 laboratories sent 2 sets and 3 laboratories sent 3 sets for a total of 66 sets. Each participant and its own sets were identified by proper alphanumerical code (ID).The list of participants is given in Table 2.

\subsection{Logistic arrangements and exposures}

The preparation of the passive devices (removal from the original packaging, etc), were performed in a room with a low radon-222 activity concentration: transits are left in this room in a radon proof bag until the end of the tests. After each test, to avoid that radon released from exposed dosimeters inside sealed packages could affect the exposure of transit devices (so called uncontrolled exposures), particular attention was paid to the management of exposed dosimeters and transits. Indeed, at the end of tests, exposed dosimeters and transits were collected and left outdoors for several days (about 3 days), before sent back to their respective laboratories.

The first two groups of passive devices were exposed in two different rooms of ARPA Piemonte building for about 5 months (154 days). In particular, the first test was held in an office at ground floor (in the following indicated as site 1) with an average radon concentration of $61 \pm 13 \mathrm{~Bq} / \mathrm{m}^{3}$, as estimated by reference continuous radon monitors (see par. 3.1). The second test occurred in a storage room in the basement (site 2), with an average radon concentration of $469 \pm 41 \mathrm{~Bq} / \mathrm{m}^{3}$ (see Table 3).

For test 3, passive dosimeters were exposed for a shorter period ( 9 days) in a cellar of a private house located in Cervo Valley (Biella, Piedmont; site 3), which has very high levels of radon and thoron. This area is characterized by the presence of syenite, an intrusive magmatic rock, very rich in uranium and thorium (more details about natural radionuclides content in (Nuccetelli et al., 2017)). The cellar had an average radon activity concentration of $2399 \pm 94 \mathrm{~Bq} / \mathrm{m}^{3}$ (see Table 3) while the average thoron activity concentration close to the wall surface was equal to $1685 \pm 389 \mathrm{~Bq} / \mathrm{m}^{3}$.

Each participant was asked to return the results in terms of radon exposure of each devices (exposed devices and transits) together with the associated uncertainty estimated with $k=1$. Moreover, it was asked to provide the radon concentration associated to each test.

\subsection{Interpretation protocol for data analysis}

As in the first edition, the protocol for the analysis of results consisted in many steps. Firstly, participants' results in terms of radon exposure were arranged in 3 datasets (one for each test). For each participant (ID), the arithmetic mean and the associated uncertainty (as standard deviations) of transits were computed.

For each device, the net value was calculated subtracting to the given value the transit contribution (as arithmetic mean). The uncertainty, $u\left(E_{\text {net }}\right)$, related to each net radon exposure $\left(E_{\text {net }}\right)$ value, was computed by the propagation of uncertainties accounting for the uncertainty of a given passive device result, $u(E)$, and the one associated to transits, $u\left(E_{t}\right)$.

$u_{i}\left(E_{n e t}\right)=\sqrt{u_{i}(E)^{2}+\left(\sum_{j=1}^{n} \frac{u_{j}\left(E_{t}\right)}{n}\right)^{2}}$

Following this protocol for each ID, on the net data main statistics e.g. arithmetic mean, median, standard deviation and coefficient of variation $(\mathrm{CV})$ - were calculated. Furthermore, as recommended by the ISO 17043:2010 (ISO, 2010), the percent difference (PD), the normalized error $\left(E_{n}\right)$ and the $z$-score have been calculated.

The percent difference $(P D)$ is a parameter, independent from the magnitude of the assigned value. It is the percent difference between a participant's test result and the reference value divided for the reference value $E_{R}$ of each test (i). $P D$ is given by the following equation: 
Table 2

List of 49 participants to the second "International Radon in-field Intercomparison". In Italic new countries respect to 2014 Intercomparison.

\begin{tabular}{|c|c|c|c|}
\hline Country (n. of participants) & Lab & Passive device & Detector \\
\hline Argentina (1) & Lab. Mediciones de radon, Aut. Reg. Nucl. & RSKS & CR-39 (Radosys) \\
\hline Australia (1) & ARPANSA & Radosure & CR-39 (Tastrak) \\
\hline Bulgaria (1) & Radon Monit. and Prev. Lab., Nat. Center of Radiobiol. Radiat. Prot. & RSKS & CR-39 (Radosys) \\
\hline Finland(1) & STUK-Radiation and Nuclear Safety Authority & Radonpurkk & Makrofol (Bayer) \\
\hline \multirow[t]{2}{*}{ France (2) } & Algade LED-UD & DPR2 & LR115 (ALGADE) \\
\hline & Algade Dosirad Laboratory & DRF DRF2 & LR115 (ALGADE) \\
\hline Greece (1) & Department of environmental radioactivity & Tasl & CR-39 (Tastrak) \\
\hline \multirow[t]{2}{*}{ Hungary(2) } & Centerfor Energy Research ofHungarian Academy of Sciences & NRPB/SSI & CR-39 \\
\hline & Radosys & RSKS & CR-39 (Radosys) \\
\hline Ireland (1) & EPA, Office of Radiological Protection & NRPB/SSI & CR-39 \\
\hline \multirow[t]{37}{*}{ Italy (33) } & ARPAL - Laboratorio di Genova & RSKS & CR-39 (Radosys) \\
\hline & APPA Trento & E-PERM Rad Elec & Electret \\
\hline & ARPA Piemonte & Tasl & CR-39 (Tastrak) \\
\hline & ARPA FVG - Centro Regionale di Radioprotezione & RSKS & CR-39 (Radosys) \\
\hline & ARPA Lazio - Roma & RSKS & CR-39 (Radosys) \\
\hline & ARPA Lombardia & RSKS E-PERM Rad Elec & CR-39(Radosys) \\
\hline & & & Electret \\
\hline & ARPA Umbria - Perugia & E-PERM Rad Elec & Electret \\
\hline & ARPA Valle d'Aosta & Radout $^{\mathrm{TM}}$ & CR-39 \\
\hline & ARPAM - Centro Regionale Radioattività Ambientale & E-PERM Rad Elec & Electret \\
\hline & ARPAS - Laboratorio Radioattività Ambientale - Cagliari & Tasl & CR-39 (Tastrak) \\
\hline & ARPAT & Tasl E-PERM Rad Elec & CR-39 (Tastrak) \\
\hline & & & Electret \\
\hline & ARPAV - Dipartimento Provinciale di Treviso & E-PERM Rad Elec & Electret \\
\hline & ARPAV - Dipartimento Regionale Laboratori & RSKS & CR-39 (Radosys) \\
\hline & CISAM & RSKS & CR-39 (Radosys) \\
\hline & ARPAB CRR & RSKS E-PERM Rad Elec & CR-39 (Radosys) \\
\hline & & & Electret \\
\hline & E-laboRAD - Università di Cagliari & PP holder $(60 \mathrm{ml})$ & CR-39 \\
\hline & European Commission - DG JRC-Joint Research Center & Radout $^{\mathrm{TM}}$ & CR-39 \\
\hline & INAIL - CONTARP - Laboratorio di Igiene Industriale & E-PERM Rad Elec & Electret \\
\hline & ISPRA - Servizio Misure Radiometriche Laboratorio Radon & RADOSURE & CR-39 (Tastrak) \\
\hline & Lab Radioattività Ambientale - S.U.N. Caserta & Plastic box RADOSURE & LR115 \\
\hline & & & CR-39 \\
\hline & INAIL - DiMEILA - Lab. Rischio Agenti Cancerogeni e Mutageni & NRPB/SSI & CR-39 (Tastrak) \\
\hline & Laborad srl & E-PERM Rad Elec & Electret \\
\hline & ARPACAL - Laboratorio Ettore Majorana- & Radout $^{\mathrm{TM}}$ & CR-39 \\
\hline & Lab.Rad. LaRa - Dip. Fisica - Università di Napoli Federico II & E-PERM Rad Elec Plastic box & $\begin{array}{l}\text { Electret } \\
\text { LR115 }\end{array}$ \\
\hline & Lavoro e ambiente srl & RSKS & CR-39 (Radosys) \\
\hline & MCF Ambiente srl & RSKS & CR-39 (Radosys) \\
\hline & Mi.am srl & Radout $^{\mathrm{TM}}$ & CR-39 \\
\hline & Radchem & E-PERM Rad Elec & Electret \\
\hline & Servizio Radon ENEA IRP-DOS & ENEA IRP-DOS & CR-39 \\
\hline & SOGIN - Lab radiochimico centrale di Garigliano & RSKS & CR-39 (Radosys) \\
\hline & ARPA Sicilia U.O. Ag. Fis. Palermo & Radout $^{\mathrm{TM}}$ & CR-39 \\
\hline & U-Series Srl & RADOSURE & CR-39(Tastrak) \\
\hline & XGAMMAGUARD & E-PERM Rad Elec Radout ${ }^{\mathrm{TM}}$ & Electret CR-39 (Intercast) \\
\hline Lithuania (1) & Radiation Protection Center & RSKS & CR-39 (Radosys) \\
\hline Russia (1) & SRC Federal Medical Biophysical Center & REI-4 & LR115 \\
\hline Slovenia (1) & ZVD ZAVOD ZA VARSTVO PRI DELU D. O. O. & RSKS & CR-39 (Radosys) \\
\hline Spain (1) & LaRUC - Universidad de Cantabria & RSKS & CR-39 (Radosys) \\
\hline Sweden (1) & Landauer Nordic AB & NRPB/SSI & CR-39 \\
\hline United Kingdom (1) & Tasl & Tasl & CR-39 (Tastrak) \\
\hline
\end{tabular}

Table 3

Radiological and environmental data related to the three sites.

\begin{tabular}{|c|c|c|c|}
\hline & Site 1 & Site 2 & Site 3 \\
\hline Average radon exposure $\left(\mathrm{kBq} \cdot \mathrm{h} / \mathrm{m}^{3}\right)$ - active measurements & $225 \pm 50$ & $1731 \pm 152$ & $516 \pm 85$ \\
\hline Average radon exposure $\left(\mathrm{kBq} \cdot \mathrm{h} / \mathrm{m}^{3}\right)$ - passive measurements & $238 \pm 22$ & $1690 \pm 121$ & $547 \pm 73$ \\
\hline Exposure time (days) & 154 & 154 & 9 \\
\hline Average radon concentration $\left(\mathrm{Bq} / \mathrm{m}^{3}\right)$ - active measurements & $61 \pm 13$ & $469 \pm 41$ & $2399 \pm 394$ \\
\hline Average radon concentration $\left(\mathrm{Bq} / \mathrm{m}^{3}\right)$ - passive measurements & $64 \pm 6$ & $457 \pm 33$ & $2543 \pm 338$ \\
\hline Altitude above sea level (m) & 253 & 253 & 846 \\
\hline Gamma dose rate $(\mathrm{nGy} / \mathrm{h})$ & $73 \pm 7$ & $106 \pm 13$ & $953 \div 1196$ (range) \\
\hline Temperature $\left({ }^{\circ} \mathrm{C}\right)$ & $20.0 \pm 0.4$ & $21.0 \pm 0.4$ & $13.2 \pm 0.3$ \\
\hline Pressure (hPa) & $989 \pm 1$ & $997 \pm 1$ & $916 \pm 1$ \\
\hline Humidity (RH\%) & $45 \pm 1$ & $52 \pm 2$ & $75 \pm 2$ \\
\hline
\end{tabular}


$P D[\%]=\frac{E_{i}-E_{R i}}{E_{R i}}$

where $E_{i}$ is the arithmetic mean of net results in terms of radon exposure

$E_{i}=\sum_{j=1}^{n} \frac{\left(E_{n e t}\right)_{j}}{n}$

The uncertainty associated to $\mathrm{E}_{\mathrm{i}}$ is given by:

$u\left(E_{i}\right)=\sum_{j=1}^{n} \frac{u\left(E_{n e t}\right)_{j}}{n}$

The normalized error $\left(E_{n}\right)$ is a tool to compare the test results accounting for the uncertainty normally used to determine conformance or non-conformance in proficiency testing. $E_{n}$ is given by the following equation:

$E_{n}=\frac{E_{i}-E_{R i}}{\sqrt{U_{\text {comp }}\left(E_{i}\right)^{2}+U\left(E_{R i}\right)^{2}}}$

where $U\left(E_{R i}\right)$ is the uncertainty related to the reference value. $U_{\text {comp }}\left(E_{i}\right)$ is the expanded uncertainty with $\mathrm{k}=1$ of a participant's result associated to the test number $i$ (ISO, 2005). Results are satisfactory if the value of $E_{n}$ is between -1 and +1 .

The $z$-score index represents a standardized measure of performance related to a given specified intercomparison exercise. The formula to calculate standard $z$-score is given below:

$z_{i}=\left(E_{i}-E_{R i}\right) / \sigma_{T}$

where $\sigma_{T}$ is the standard deviation for proficiency assessment chosen as a target for the intercomparison exercise. In this exercise was decided as target $\sigma_{T}=20 \%$ of the reference value.

Results in terms of $z$-score are discussed following the ISO/IEC 17043:2010 (ISO, 2010) and ISO 13528:2005 (ISO, 2005): in particular

- results with $|z|<2$ are acceptable;

- results with $2<|z|<3$ are not completely accettable;

- results with $|z|>3$ are not accetable.

As previously said, the main scope of the intercomparison was to study the response of different types of radon passive devices in in-field conditions. To reach this scope, a restricted analysis was performed on data sets, not considering results having $z$-score $>3$ (following named as "n.a.d", not acceptable data).

\section{Results and discussion}

\subsection{Reference values}

As previously said, the reference value relevant to each site was obtained by using only active monitors with the best performance, also in term of low background: in Fig. 4 the intrinsic background of the different active monitors are shown. The relevant uncertainty has been evaluated as the standard deviation of readings, ranging from $4.3 \mathrm{~Bq} /$ $\mathrm{m}^{3}$ to $15.3 \mathrm{~Bq} / \mathrm{m}^{3}$ in term of radon values.

Looking at the graph in Fig. 4, it is evident a wide spread of the blank of analysed active radon monitors: in particular, the higher values were provided by ENEA-INMRI active monitors generally operating in the chambers at very high radon values (several tens of $\mathrm{kBq} / \mathrm{m}^{3}$ ).

In Table 3 main radiological and environmental data relevant to the three sites are summarized. It is worth to note that as for radon values, data concerning temperature, pressure and relative humidity are the overall averages during tests. Regarding gamma dose rate for the first two sites the values are homogenous over the room so the mean value is reported; conversely, in case of site 3 , due to a large spatial inhomogeneity, the overall range is given.

Looking at Table 3, it is evident the good agreement between radon data achieved with active and passive methods: the standard deviation of the passive measurements is equal to the uncertainty of the single value $(13 \%)$ and all the values belong to the same statistical population; moreover, the inhomogeneity of radon concentration in the space is negligible.

For the site 3, affected by high thoron levels, a comparison of radon results achieved hourly by different active monitors was made. As during tests in mixed radon/thoron atmosphere (par. 2.1.2) the authors confirmed a different behavior of some active monitors. In particular, the results relevant to EQF 3220 and NG AlphaGuard are in good agreement since these monitors are free from thoron influence due to their own features. The EQF 3220 detector is based on alpha spectrometry while NG AlphaGuard is provided of a dedicated measurement

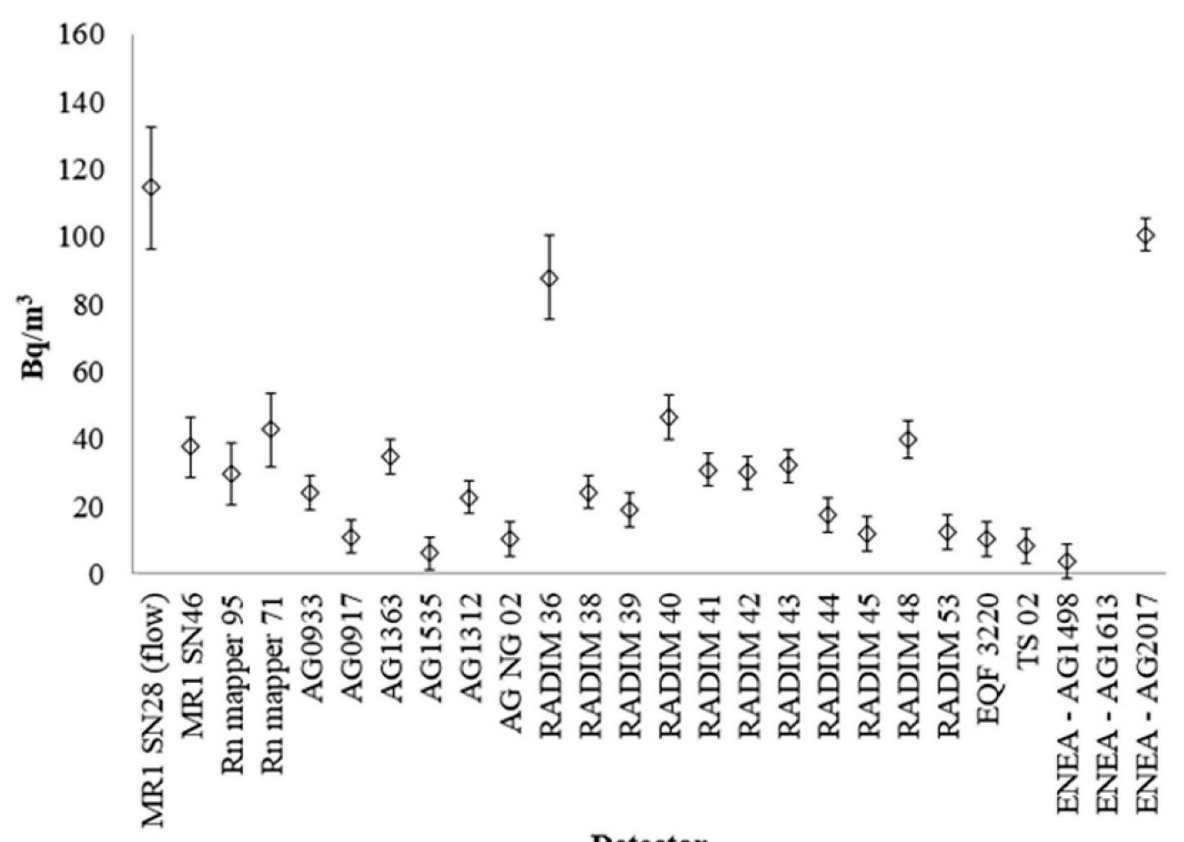

Fig. 4. Intrinsic background of different active monitors ("blank”). 


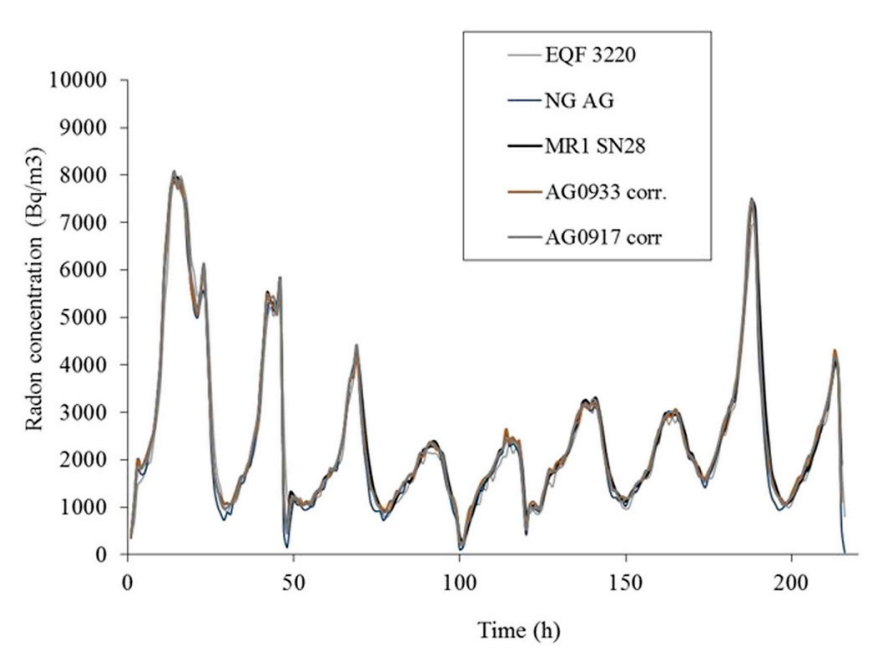

Fig. 5. Time variation of radon concentrations in site 3 recorded by several active monitors. AlphaGuard radon readings were corrected by a factor of $0.95 \%$ to account for thoron interference.

protocol called "Thoron protocol". Conversely, the "old generation" AlphaGuard shows an interference of thoron confirming what evidenced in literature (Kochowska et al., 2009; Tripathi et al., 2012; Sumesh et al., 2013): considering thoron concentrations in site 3 the AlphaGuard readings required the application of a correction factor of $0.95 \%$. In Fig. 5 a comparison of radon results of different active monitors after proper correction is shown.

About indoor thoron levels in site 3, a comparison between data achieved by EQF 3220 and NG AlphaGuard are shown in Fig. 6. The values recorded by the two monitors are in good agreement and did not show any daily periodical variation.

About the gamma dose rate, in the site 1 and 2 the field was uniform $(\mathrm{AM}=73 \mathrm{nGy} / \mathrm{h} \pm 10 \%$ and $106 \mathrm{nGy} / \mathrm{h} \pm 12 \%$ for site 1 and site 2 , respectively). For the site 3 a representation of the spatial distribution of the gamma dose rate field is in Fig. 7. In order to assign to each participant device the proper gamma dose rate value -, an interpolation of the experimental data using as weights the $1 / \mathrm{r}^{2}$ function, with the software package $\mathrm{R}$ has been made.

\subsection{Overall presentation of data}

Totally 49 laboratories from 14 Countries participated to the intercomparison: 48 of them provided results. The total number of participants and the number of countries confirmed the great interest of radon laboratory for in-field proficiency tests: a slight increment respect

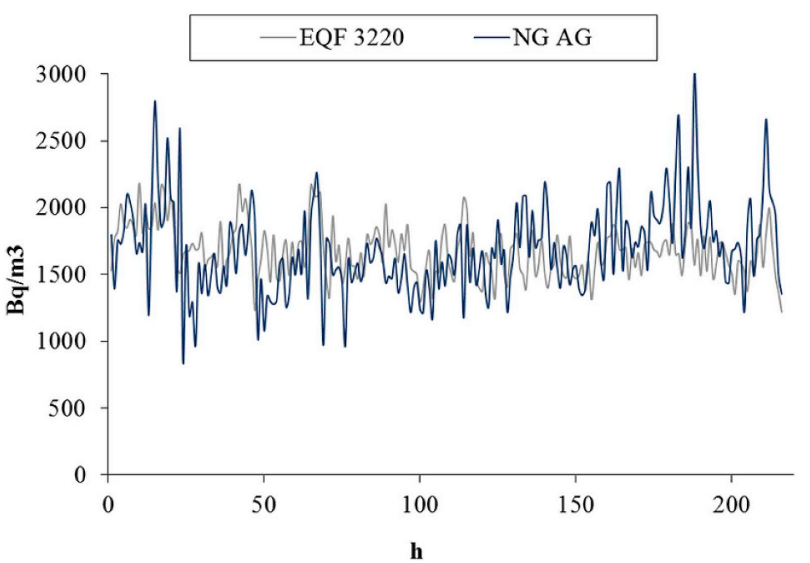

Fig. 6. Time variation of thoron concentrations in site 3, recorded by EQF 3220 and NG AlphaGuard.

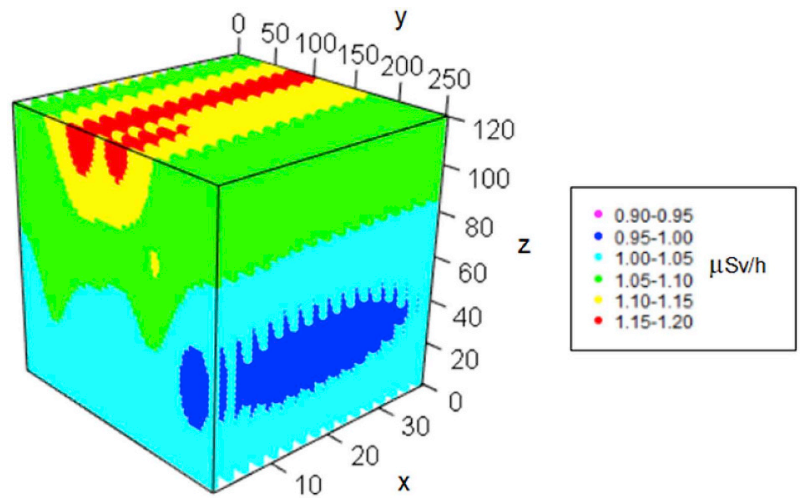

Fig. 7. Spatial distribution of the gamma dose rate field in site 3 .

to the first edition (46 participants from 13 countries) occurred. About the detectors, they were mostly SSNDT (79\%) and electrets $(21 \%)$. Looking at track detectors devices: $67 \%$ was of CR-39-based, $11 \%$ of LR115-based and 1\% of Makrofol-based.

Laboratories returned results together with a filled questionnaire: as said, participants were asked to provide results as in terms of radon exposure of all devices (exposed and transit), as in terms of average radon concentration of each test. More than $90 \%$ of participants provide all the information required.

Considering test 1 and test 2, the overall dataset contained 66 sets of data: 64 complete results in terms of radon exposure and radon concentration, while two laboratories gave results only about devices' radon exposures. Regarding the test 3 , the overall dataset contained 59 complete results in terms of radon exposure and radon concentration, two participants provided only results as radon exposure. Moreover, three laboratories provides also results about thoron exposure.

Starting from data provided by participants an analysis about intralaboratory variation of results was performed in order to evaluate the reproducibility of the measurement methods based on SSNTD or electrets: for this aim, CV relevant each set was computed and the distribution of CVs was analysed. A brief summary is reported in Table 4. It can be observed that generally for all the tests SSNTD exhibit better performances than electrets, whatever statistical parameter is considered. Even if, it is worth to note that in case of test 2 (average radon concentration $=469 \pm 41 \mathrm{~Bq} / \mathrm{m}^{3}$ ), the difference of the reproducibility for two methods is not so remarkable. For test 1 , where the radon concentration is very low $\left(61 \pm 13 \mathrm{~Bq} / \mathrm{m}^{3}\right)$, the AM of CV's for SSNTD increases by about $7 \%$ with a maximum of $56 \%$, respect to test 2 . For the electrets instead the increase is much greater and is about $37 \%$ with a maximum of $137 \%$.

For test 3 (average radon concentration $=2399 \pm 394 \mathrm{~Bq} / \mathrm{m}^{3}$ ), the average value of CV (as AM) is $29 \%$, probably due to the effect of high humidity rate and/or of a high and not uniform gamma radiation field. Looking at the CVs distribution in test 1 and 3 for the electrets almost the half of data is found above the 3rd quartile (51\% and $46 \%$ for test 1 and 3, respectively), while for SSNTD just $13 \%$ and $7 \%$ of data are above 3rd quartile.

\subsection{Effect of long-time sampling - analysis of results of test 1 and test 2}

A long-time sampling can affect detectors response producing a sensitivity decrease (generally known as fading), due to the effect of environmental parameters, in particular the temperature. Indeed, fading effect affects the etching velocity so the mean track dimensions reduce (diameter). This phenomenon has been observed for PADC (CR39) detectors: studies carried out in controlled conditions found that ageing and fading effects can produce a decrease in the CR-39 detector sensitivity leading to an underestimation of the radon concentration up to $40 \%$ for exposure time lasting few months. Moreover, it was found 
Table 4

Main statistical parameters of CV relevant each set of passive dosimeters.

\begin{tabular}{lllll}
\hline & Parameters & Test 1 & Test 2 & Test 3 \\
\hline \multirow{2}{*}{ SSNTD } & Mean & $11 \%$ & $4 \%$ & $6 \%$ \\
& Max & $56 \%$ & $15 \%$ & $27 \%$ \\
& Min & $1 \%$ & $1 \%$ & $1 \%$ \\
& Standard deviation & $10 \%$ & $3 \%$ & $4 \%$ \\
& median & $7 \%$ & $3 \%$ & $5 \%$ \\
& 3rd quartile & $13 \%$ & $5 \%$ & $7 \%$ \\
\hline \multirow{2}{*}{ Electrets } & Mean & $47 \%$ & $10 \%$ & $29 \%$ \\
& Max & $137 \%$ & $62 \%$ & $72 \%$ \\
& Min & $7 \%$ & $2 \%$ & $3 \%$ \\
& Standard deviation & $45 \%$ & $18 \%$ & $24 \%$ \\
& median & $38 \%$ & $4 \%$ & $24 \%$ \\
& 3rd quartile & $51 \%$ & $8 \%$ & $46 \%$
\end{tabular}

that CR-39 detectors by different manufacturers may have different response (Caresana et al., 2011, 2010).

Also, Franci et al. (2015) found that the sensitivity of CR-39 detectors (manufactured by Radosys, Ltd) continuously exposed in a reference radon chamber at room temperature over 3 and 6 months reduced by 4 and 7.5\%, respectively. Recently, Venoso et al. (2016) carried out a study to evaluate both the average and the variability of ageing and fading effects in real conditions, by using CR-39 (Radosys, Ltd.) and LR115 (Kodak) passive devices. In case of CR-39, radon annual average values estimated over a 12-month long period were found on average $16 \%$ lower than those estimated with two consecutive 6 months samplings. Conversely, in case of LR115 passive devices, radon measurements over 12-months period sampling did not significantly differ from those estimated with two consecutive 6-months period long samplings. About electrets, no fading effect was observed (Kotrappa, 2008), and the appropriate calibration factors mainly account for the discharge of detectors over a time and their mid-point voltages.

Analysing test 1 and test 2 net data sets, arithmetic means, medians, standard deviations and CVs were computed (see Table 4). Fig. 8 and Fig. 9 give an overview of participants' results: in particular, in both figures for each ID set, the arithmetic mean and associated uncertainty (see eq. (4)) are plotted; moreover, the reference value provided by active monitors with the associated uncertainty $(k=1)$ is shown.

For most of the data a very good agreement with reference values, within the associated uncertainties can be observed: radon passive devices did not show any significant long-time sampling effect for high and low radon average levels as well.

Table 5 summarizes main statistic parameters as a measure of general performance of all the radon passive devices. It can be seen that as for test 1 as for test 2 , the values of overall arithmetic mean and the median are very close to each other, indicating that participants' results are symmetrically distributed. Furthermore, the low values of standard deviations and coefficient of variation (CVs) highlight results very slightly spread out, nevertheless in Figs. 8 and 9 it is evident how few data are far from the reference values. In both tests, arithmetic means and medians are in good agreement with reference values, accounting for the associated uncertainties.

A further analysis was done on a restricted dataset in order to evaluate the performance of different type of detectors (SSNTD, CR-39based and electrets): data with $z$-score $>3$ were not considered since, according to the ISO13528 standard (ISO, 2005), a z-score $>3$ represents a not acceptable result. Results are in Table 5.

Looking at the arithmetic means, medians and PD averages of SSNTD devices and CR-39-based ones, a slight underestimation trend is observed: SSNTD and CR-39-based data results are very similar due to the scarce number of participants using LR115-based and Makrofol.

These findings could confirm previous studies. However, the underestimation attributable to fading effect on CR-39 detectors is much lower than that found in the literature: these results put in evidence that, at least during the proficiency tests, laboratories are able to manage the phenomenon using corrective procedures of analytical data, such as algorithms in automatic counting systems. Conversely, results achieved by electrets are in good agreement with reference values with a tendency to an overestimation at low radon exposures $(P D=12 \%)$.

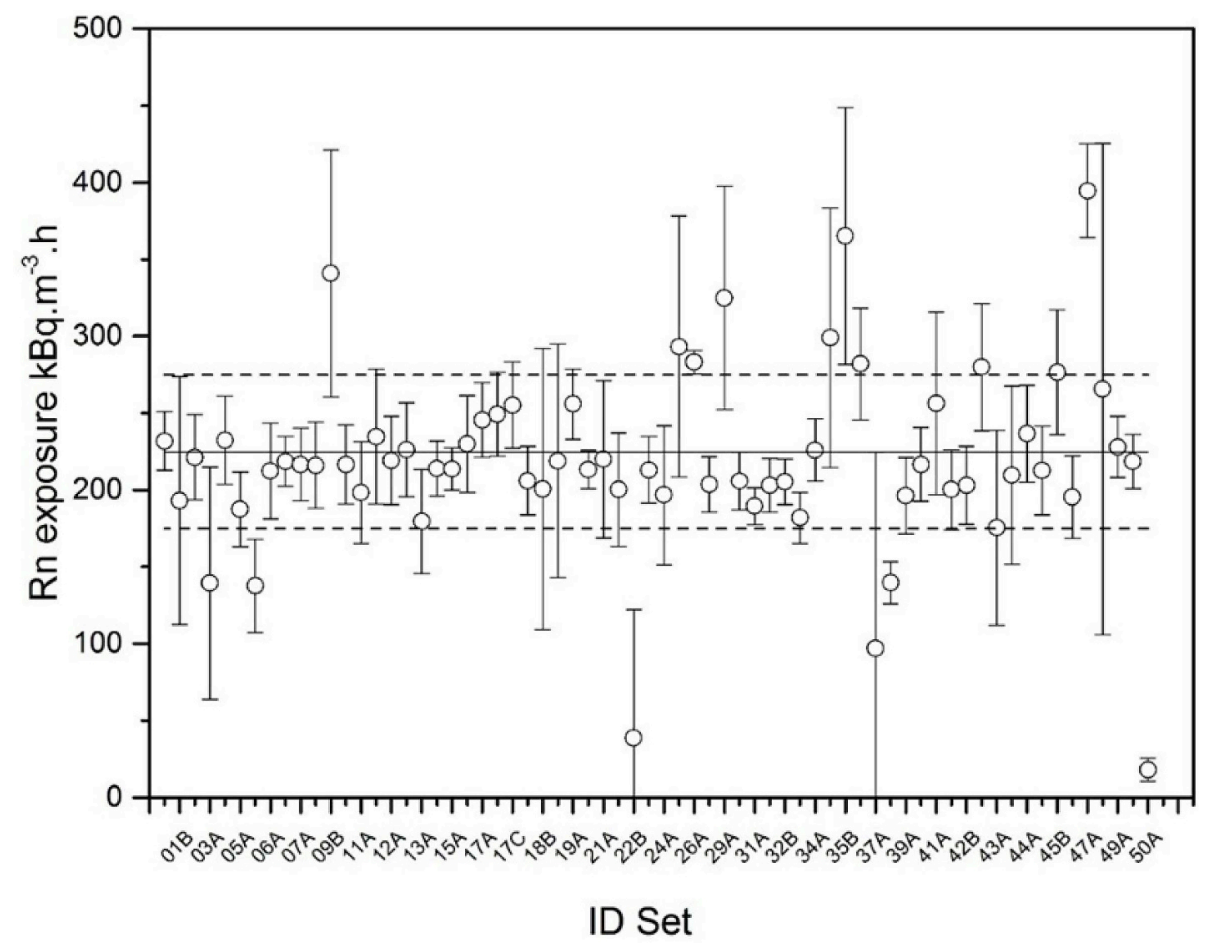

Fig. 8. Test 1: synthesis of results of participants. For each ID, arithmetic mean with the associated uncertainty. The reference value $\left(225 \pm 50 \mathrm{kBq} \mathrm{m}^{-3} \mathrm{~h}\right)$ together with his uncertainty $(\mathrm{k}=1)$ is plotted (respectively the solid grey and the dashed lines). 


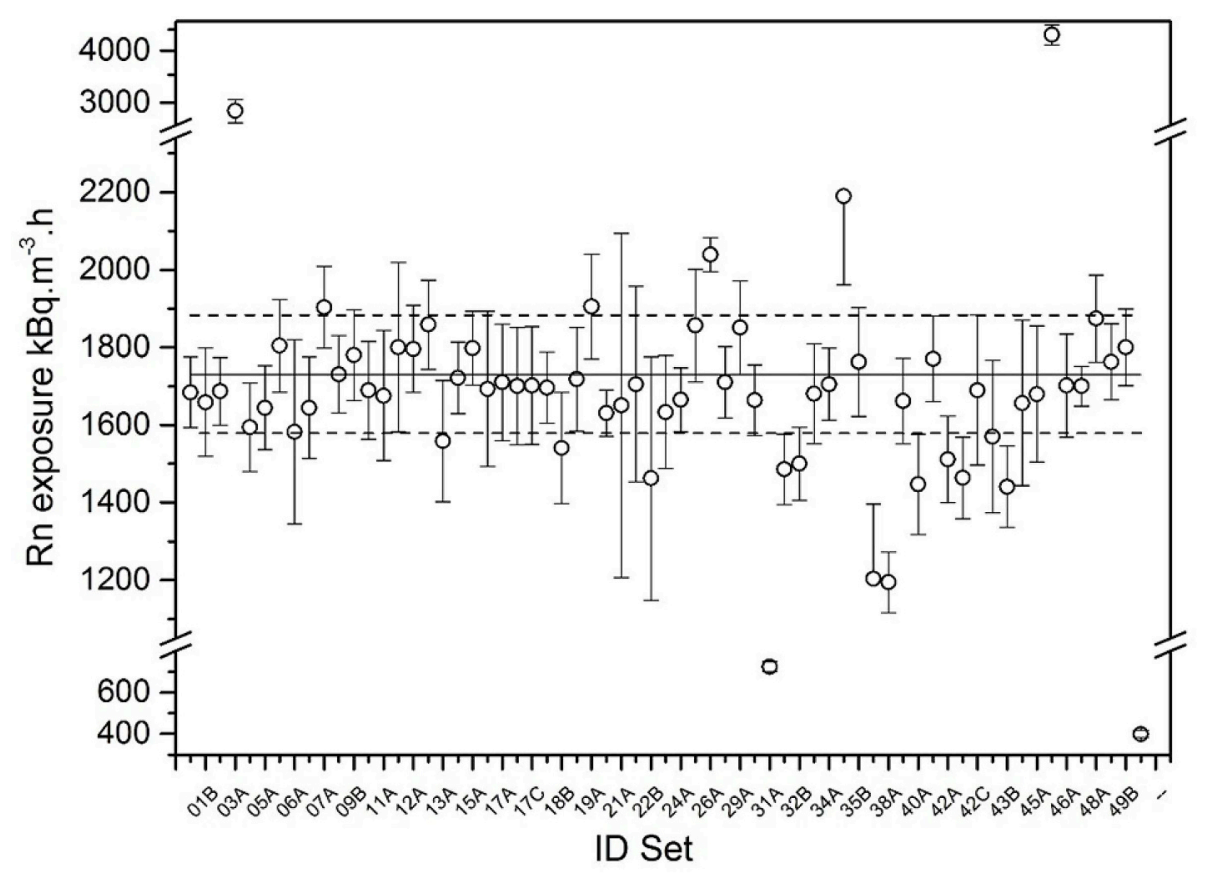

Fig. 9. Test 2: synthesis of results of participants. For each ID, arithmetic mean with the associated uncertainty. The reference value (1731 $\pm 152 \mathrm{kBq} \mathrm{m}^{-3} \mathrm{~h}$ ) together with his uncertainty $(\mathrm{k}=1)$ is plotted (respectively the solid grey and the dashed lines).

Table 5

Synthesis of results of test 1 and test 2 - main statistic parameters.

\begin{tabular}{|c|c|c|c|c|c|}
\hline \multirow[t]{2}{*}{ Test 1} & Ref. value & $\mathrm{AM} \pm \mathrm{SD}$ & Median & $\mathrm{CV}$ & PD avg \\
\hline & \multicolumn{3}{|l|}{$\mathrm{kBq} \cdot \mathrm{h} / \mathrm{m}^{3}$} & \multicolumn{2}{|l|}{$\%$} \\
\hline Overall & $225 \pm 50$ & $219 \pm 60$ & 216 & 27 & -3 \\
\hline $\begin{array}{l}\text { SSNTD devices, without } \\
\text { n.a.d }\end{array}$ & & $213 \pm 34$ & 213 & 16 & -6 \\
\hline $\begin{array}{l}\text { CR39 devices, without } \\
\text { n.a.d }\end{array}$ & & $208 \pm 31$ & 213 & 15 & -8 \\
\hline $\begin{array}{l}\text { Electrets devices, } \\
\text { without n.a.d }\end{array}$ & & $252 \pm 58$ & 261 & 23 & 12 \\
\hline \multicolumn{6}{|l|}{ Test 2} \\
\hline Overall & $1731 \pm 152$ & $1707 \pm 446$ & 1690 & 26 & -1 \\
\hline $\begin{array}{l}\text { SSNTD devices, without } \\
\text { n.a.d }\end{array}$ & & $1653 \pm 215$ & 1680 & 13 & -5 \\
\hline $\begin{array}{l}\text { CR39 devices, without } \\
\text { n.a.d }\end{array}$ & & $1637 \pm 213$ & 1678 & 13 & -5 \\
\hline $\begin{array}{l}\text { Electrets devices, } \\
\text { without n.a.d }\end{array}$ & & $1725 \pm 124$ & 1740 & 7 & -0.4 \\
\hline
\end{tabular}

n.a.d $=$ Not acceptable data defined as data with $z$-score $>3$, see Table 7 . $\mathrm{AM}=$ arithmetic mean.

$\mathrm{SD}=$ standard deviation.

$\mathrm{CV}=$ coefficient of variation.

$\mathrm{PV}=$ percent difference (defined in eq. (2)).

3.4. Effect of simultaneous presence of radon/thoron - analysis of results of test 3

In Fig. 10 and Table 6 a synthesis of results of test 3 is given: main statistic parameters are shown. Looking at the overall results, the mixed radon/thoron atmosphere seems to lead to an overestimation of radon exposure (overall arithmetic mean $=591 \mathrm{kBq} \cdot \mathrm{h} / \mathrm{m}^{3}$ respect to the reference value $=516 \pm 85 \mathrm{kBq} \cdot \mathrm{h} / \mathrm{m}^{3}$ ), and a large variability of results (standard deviation $=318 \mathrm{kBq} \cdot \mathrm{h} / \mathrm{m}^{3}$ ). In test 3 , the value of the $\mathrm{CV}$ is about twice the one estimated for test 1 and test 2 . However, excluding not acceptable data ("n.a.d"), different conclusions can be drawn: arithmetic mean and median values of SSNTD devices are similar and in very good agreement with reference value and results appear not so scattered $(\mathrm{CV}=15 \%)$. In this case, the error caused by an eventual thoron interference is smaller than the measurement uncertainty so the interference of thoron can be neglected.

Looking at the information provided by participants, in several cases the unsatisfactory performances seems not strictly connected with the type of detector used; it could be rather attributed to incorrect management procedure (e.g. in the management of data concerning transits).

\subsection{Discussion of overall results by using z-score and $E_{n}$}

As previously said in par. 2.4, the results in terms of $z$-score is carried out are discussed according to the ISO/IEC 17043:2010 (ISO, 2010) and ISO 13528:2005 (ISO, 2005).

Distributions of absolute values of $z$-score ( $|z|)$ for all the tests are summarized in Table 7 . For test 1 , the $89 \%$ of results are acceptable and only $6 \%$ is not. In case of test 2 , in presence of high radon levels the percentage of results considered acceptable increases up to $94 \%$ and those not acceptable are equal to $5 \%$. These findings are in good agreement with previous comments: as for both high and low radon exposures, the symmetric distribution of laboratories' results and the values of the overall arithmetic means and medians are close to each other. These results confirm that the long-time sampling (fading) does not affect the reliability of integrated radon measurements or laboratories have good procedures able to manage fading effects.

In case of test 3 , a decrease of the percentage of results considered acceptable $(\mathrm{z} 80 \%=2>1)$ was observed, while the percentage of results not completely acceptable and not acceptable increased to $8 \%$ and $12 \%$, respectively. While a $z$-score exceeding 3 clearly calls for action, a $z$-score in the range 2-3 does not in itself say that all is well. Even with an uncertainty equals to twice the value of standard deviation, a participant would still obtain a $z$-score in the range of 2 with a probability of $67 \%$ (AMC, 2016).

The $z$-score is an important parameter but it needs to be completed by the discussion of $E_{n}$ values. According to the ISO 13528:2015 standard (ISO, 2005), " $E_{n}$ can be useful when an objective for the proficiency testing scheme is to evaluate a participant's ability to have 


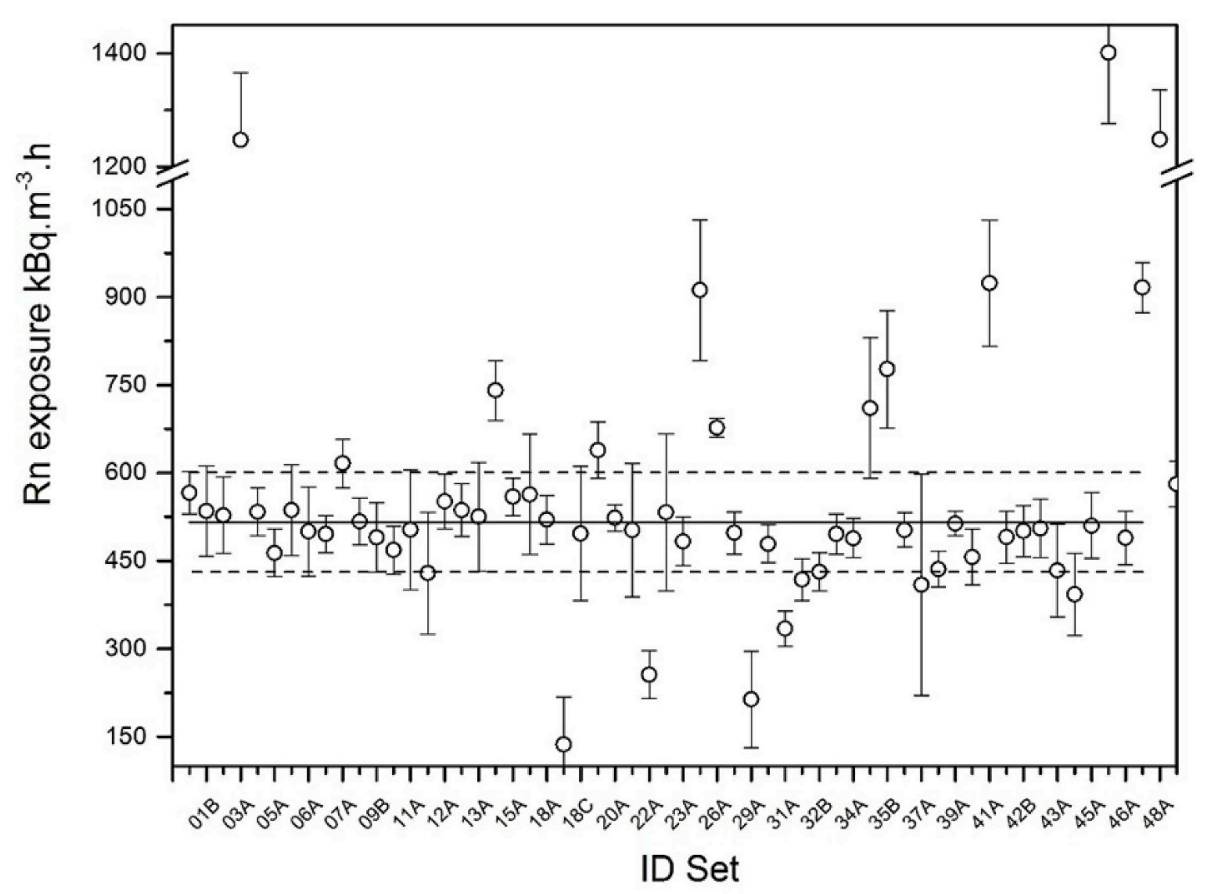

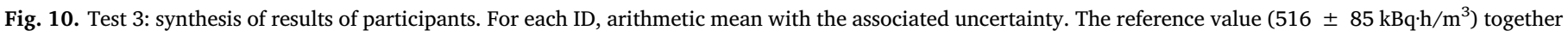
with his uncertainty $(\mathrm{k}=1)$ is plotted (respectively the solid grey and the dashed lines).

Table 6

Synthesis of results of test 3 - main statistic parameters.

\begin{tabular}{llllll}
\hline Test 3 & Ref.value & $\mathrm{AM} \pm \mathrm{SD}$ & Median & $\mathrm{CV}$ & PDavg \\
\cline { 2 - 6 } & $\mathrm{kBq} \cdot \mathrm{h} / \mathrm{m}^{3}$ & & & $\%$ & \\
\hline Overall & $516 \pm 85$ & $591 \pm 318$ & 510 & 54 & 15 \\
SSNTD device, without n.a.d & & $513 \pm 79$ & 503 & 15 & -0.5 \\
CR-39 device, without n.a.d & & $509 \pm 74$ & 501 & 15 & -1 \\
Electrets device, without n.a.d & & $482 \pm 166$ & 503 & 34 & -7 \\
\hline
\end{tabular}

Electrets data put in evidence a slight underestimation, in terms of arithmetic mean, median and percent difference $(P D=-7 \%)$, and a high coefficient of variation $(\mathrm{CV}>34 \%)$.

n.a.d $=$ Not acceptable data defined as data with $z$-score $>3$, see Table 7 .

$\mathrm{AM}=$ arithmetic mean.

$\mathrm{SD}=$ standard deviation.

$\mathrm{CV}=$ coefficient of variation.

$\mathrm{PV}=$ percent difference (defined in eq. (2)).

Table 7

Synthesis of results of the analysis of $z$-score in the three tests.

\begin{tabular}{|c|c|c|c|c|c|c|}
\hline z-score & \multicolumn{2}{|l|}{ Test 1} & \multicolumn{2}{|l|}{ Test 2} & \multicolumn{2}{|l|}{ Test 3} \\
\hline$|z|<2$ & $89 \%$ & & $94 \%$ & & $80 \%$ & \\
\hline $2<|z|<3$ & $5 \%$ & & $2 \%$ & & $8 \%$ & \\
\hline$|z|>3$ & $6 \%$ & & $5 \%$ & & $12 \%$ & \\
\hline $\begin{array}{l}\text { Results } \\
\text { without } \\
\quad \text { n.a.d }\end{array}$ & SSNTD & Electrets & SSNTD & Electrets & SSNTD & Electrets \\
\hline$|z|<2$ & $98 \%$ & $83 \%$ & $98 \%$ & $100 \%$ & $98 \%$ & $67 \%$ \\
\hline $2<|z|<3$ & $2 \%$ & $17 \%$ & $2 \%$ & $0 \%$ & $2 \%$ & $33 \%$ \\
\hline
\end{tabular}

results close to the assigned value within their claimed expanded uncertainty". If the value of $E_{n}$ is $<-1$ or $>1$, it is necessary to correct measurement's issues and/or to review the uncertainty estimation. An analysis of the percentages of participants with satisfactory results $\left(-1<E_{n}<1\right)$ is given in Fig. 11, where for each test $E_{n}$ is plotted according to the types of passive device.

As for test 1 as for test 2, the analysis of overall data (including n.a.d.) gives very good results: $97 \%$ and $92 \%$ of results exhibits respectively an $-1<E_{n}<1$. Results improve further if n.a.d are not considered: in this case $100 \%$ of the results had $-1<E_{n}<1$ for both tests. The same phenomenon is found analysing separately data of electrets and SSNTD (both without n.a.d). In particular, electrets exhibit $100 \%$ of results within $-1<E_{n}<1$ for both tests, while the SSNTD have $100 \%$ and $94 \%$ of results within $-1<E_{n}<1$ for tests 1 and 2, respectively. This last result seems to be partially in contrast with the one achieved in terms of $z$-score, where for both tests the SSNTD data showed a $98 \%$ of results with $|z|<2$ (see Table 7). In order to explain such phenomenon, a consideration about the evaluation of the uncertainty has to be done: higher values of the uncertainty at low radon exposure lead apparently to better performance of the SSNTD devices in term of $E_{n}$ in test 1 respect test 2 . Indeed, in case of test 1 only $29 \%$ of results have an uncertainty below $10 \%$ compared with the $78 \%$ for test 2: this evidence highlights the need to reduce uncertainties associated to radon measurements especially at low radon values. The need to an accurate and reliable radon exposure assessment at low values is enforced by the progressive decreasing of radon reference levels required by the international bodies, such as ICRP (ICRP, 2007), IAEA (IAEA, 2014), WHO (World Health Organization, 2009) and EU (European Commission, 2014).

A completely different scenario was found in test 3: only $89 \%$ and $92 \%$ of the overall results have an $E_{n}$ score between -1 and +1 with and without n.a.d, respectively. This value is mostly influenced by the not fully satisfactory performances of the electrets (only $78 \%$ with $-1<E_{n}<1$ ), respect to the $96 \%$ of SSNTD devices. As previously mentioned, this evidence is in good agreement with results analysed in term of $z$-score: actually, only $67 \%$ of electrets' results exhibits a $|z|<2$ (see Table 7).

\section{Final comments and conclusions}

Recently, the second "International radon in-field intercomparison for passive measurement devices: dwellings and workplaces" has been 


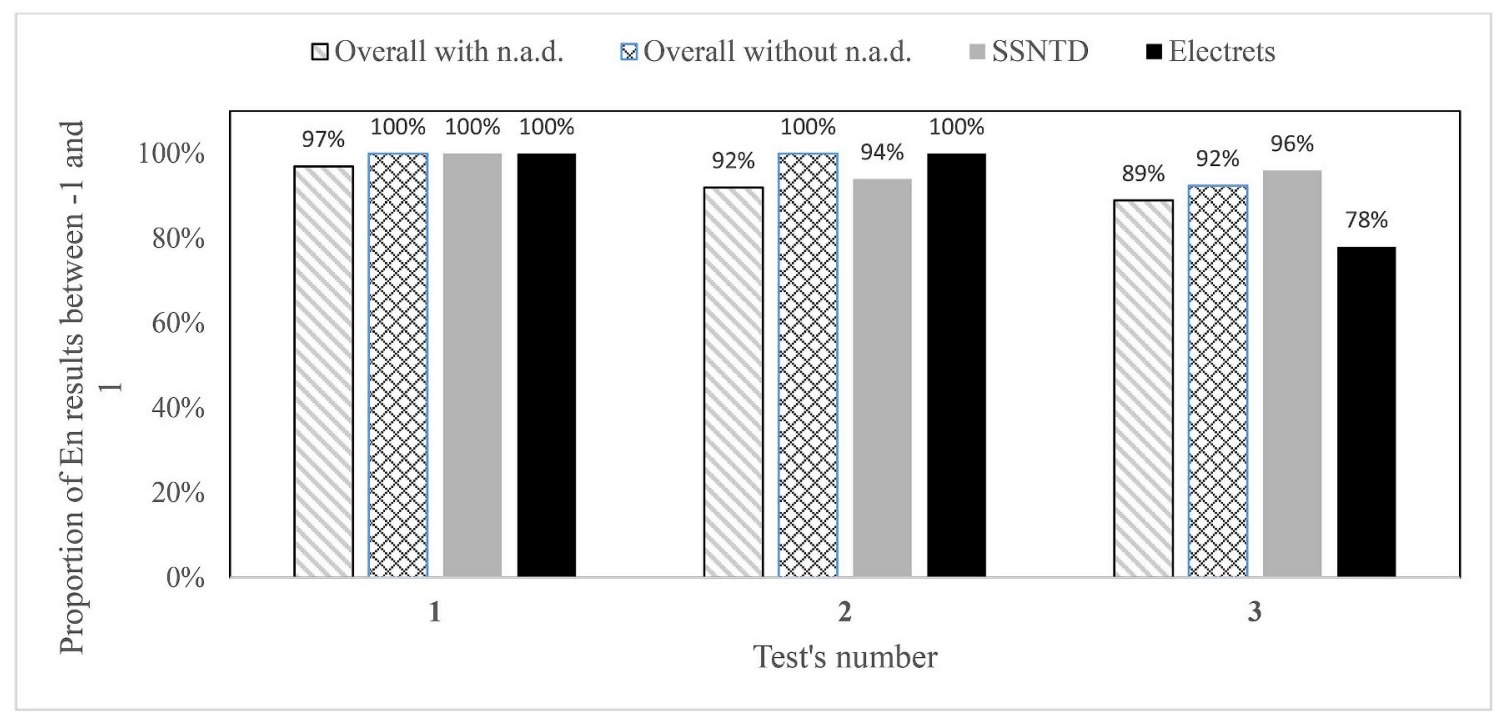

Fig. 11. Synthesis of results of participants in the three test: the distribution of $E_{n}$ values is given. For electrets and SSNTD, n.a.d are not considered.

organized. The objective was to test if radon laboratories can provide accurate and reliable measurements, drawing attention on two different issues: the effect of long-time sampling at low and high radon levels and the effect of the simultaneous presence of radon and thoron.

The radon measurements services and laboratories participating to the intercomparison appreciated the possibility to test their systems during in-situ exercises, with exposures having place in real conditions, which are less controlled and much more variable, very similar to the ones in which devices are normally exposed.

The preparatory calibration procedures of the active monitors covered the following aspects: efficiency and intrinsic background (blank) evaluation; response to several radon activity concentration ranges, influence of the thoron concentration. The use of different instruments was useful to highlight some metrological aspects and critical issues that are not considered in the standard quality procedures and that have to be investigated.

Looking at overall radon concentration results for test 1 and 2, no particular evident effect of the long-time sampling (fading) has been observed. However, some laboratories may have accounted for fading effect and have implemented procedure for the correction of results. The analysis of CV relevant each set of passive dosimeters highlighted especially in test 1 the higher variability of the results for electret devices (average CV for electrets is equal to $47 \%$ while for SSNTDs is equal to $11 \%$ ). The comparison between results obtained in terms of $E_{n}$ and $z$-score for test 1 , point out the need to improve not only the accuracy of measurements at low radon level bot also reduce the contribution of uncertainty of the estimated value.

The results of the test performed with a simultaneous presence of radon and thoron apparently lead to general overestimation of radon exposure (looking at arithmetic means) and a certain variability of results. However, excluding outliers ("n.a.d"), different conclusions can be drawn: arithmetic mean and median values of the overall dataset and of the SSNTD devices are similar and in good agreement with reference value: the interference of thoron is thus negligible. Conversely, in case of electrets data, a slight underestimation has been observed in terms of arithmetic mean, median and percent; moreover, data showed a high coefficient of variation ( $\mathrm{CV}>34 \%$ ). Analysing the overall performances of the electrets in test 3 several critical aspect seems to be come out. In particular, also without considering n.a.d., only $67 \% \%$ of electret has $1 z 2>1$, this results could be attributed to several reasons such as: presence of thoron, high and not homogenous gamma dose rate field and high humidity rate.

Looking at the information provided by participants, in several cases the unsatisfactory performances seems not strictly connected with the type of detector used; it could be rather attributed to incorrect management procedure (e.g. in the management of transit data).

\section{References}

AMC, 2016. Z -Scores and other scores in chemical proficiency testing - their meanings, and some common misconceptions. Anal. Methods 8, 5553-5555. https://doi.org/10. 1039/c6ay90078j.

Cardellini, F., Chiaberto, E., Garlati, L., Giuffrida, D., Leonardi, F., Magnoni, M., Minchillo, G., Prandstatter, A., Serena, E., Trevisi, R., Tripodi, R., Veschetti, M., 2016a. Main results of the international intercomparison of passive radon detectors under field conditions in Marie Curie's tunnel in Lurisia (Italy). Nukleonika 61. https://doi.org/10.1515/nuka-2016-0042.

Cardellini, F., Chiaberto, E., Garlati, L., Giuffrida, D., Leonardi, F., Magnoni, M., Minchillo, G., Prandstatter, A., Serena, E., Trevisi, R., Tripodi, R., Veschetti, M., 2016b. Metrological aspects of international intercomparison of passive radon detectors under field conditions in Marie Curie's tunnel in Lurisia. Nukleonika 61. https://doi.org/10.1515/nuka-2016-0043.

Cardellini, F., De Felice, P., Pagliari, M., 2013. Determination of blank indication of active radon monitors. Appl. Radiat. Isot. 81, 242-247. https://doi.org/10.1016/j.apradiso. 2013.03.093.

Caresana, M., Ferrarini, M., Garlati, L., Parravicini, A., 2011. Further studies on ageing and fading of CR39 PADC track detectors used as air radon concentration measurement devices. Radiat. Meas. 46 (10), 1160-1167. https://doi.org/10.1016/j.radmeas. 2011.07.040.

Caresana, M., Ferrarini, M., Garlati, L., Parravicini, A., 2010. About ageing and fading of Cr-39 PADC track detectors used as air radon concentration measurement devices. Radiat. Meas. 45, 183-189.

European Commission, 2014. Council directive 2013/59/Euratom of 5 December 2013. Off. J. Eur. Union. https://doi.org/10.3000/19770677.L 2013.124.eng.

Franci, D., Aureli, T., Cardellini, F., 2015. Study of ageing and fading in CR-39 detectors for different storage conditions. Radiat. Prot. Dosim. 167 (4), 425-428. https://doi. org/10.1093/rpd/ncu360.

Gutiérrez-Villanueva, J.L., Sainz Fernandez, C., Fuente Marino, I., Quindos Lopez, L., Quindos Lopez, J., Fernandez Villar, A., Casal Ordas, S.E., Lopez Abascal, D., Artheche Laso, D., Fernandez Lopez, E., Quindos Poncela, L.S., 2012. International Intercomparison Exercise on Natural Radiation Measurements under Field Conditions. PUbliCan Edicione Universidad de Cantabria.

IAEA, 2014. Radiation protection and safety of radiation sources: international basic safety standards. Basic Saf. Stand. Int. At. Energy Agency Vienna GSR Part 3 STI/ PUB/1578.

ICRP, I.C. on R.P., 2007. The 2007 Recommendations of the International Commission on Radiological Protection. Annals of the ICRP ICRP Publication 10337 (2-4). https:// doi.org/10.1016/j.icrp.2004.12.002.

IEC 61577-4, 2009. Radiation Protection Instrumentation - Radon and Radon Decay Product Measuring Instruments - Part 4: Equipment for the Production of Reference Atmospheres Containing Radon Isotopes and Their Decay Products (STAR)., 2009.

Ishikawa, T., 2004. Effects of thoron on a radon detector of pulse-ionization chamber type. Radiat. Prot. Dosim. 108 (4), 327-330. https://doi.org/10.1093/rpd/nch037.

ISO, 2017. ISO/IEC 17025: general requirements for the competence of testing and calibration laboratories. Int. Stand. https://doi.org/10.1109/IEEESTD.2015.7106438.

ISO, 2010. ISO/IEC 17043:2010 General requirements for proficiency testing. Int. Stand.

ISO, 2005. ISO 13528:2005 Statistical methods for use in proficiency testing by interlaboratory comparisons. Int. Stand. 
Kochowska, E., Kozak, K., Kozłowska, B., Mazur, J., Dorda, J., 2009. Test measurements of thoron concentration using two ionization chambers AlphaGUARD vs. radon monitor RAD7. Nukleonika 54 (3), 189-192.

Kotrappa, P., 2008. Long term stability of electrets used in electret ion chambers. J. Electrost. 66 (7-8), 407-409. https://doi.org/10.1016/j.elstat.2008.04.008.

Kotrappa, P., Dempsey, J.C., Hickey, J.R., Stieff, L.R., 1988. An electret passive environmental 222Rn monitor based on ionization measurement. Health Phys. 54, 47-56.

Michielsen, N., Bondiguel, S., 2015. The influence of thoron on instruments measuring radon activity concentration. Radiat. Prot. Dosim. 176 (1-3), 289-292. https://doi. org/10.1093/rpd/ncv264.

Nuccetelli, C., Risica, S., Onisei, S., Leonardi, F., Trevisi, R., 2017. Natural Radioactivity in Building Materials in the European Union: a Database of Activity Concentrations and Radon Exhalations 17/36 Rapporti ISTISAN.

Roca, V., Boiano, A., Esposito, A., Guardato, S., Pugliese, M., Sabbarese, M., Venoso, G., 2004. A monitor for continuous and remote control of radon level and environmental parameters. IEEE Symposium Conference Record Nuclear Science 2004, vol. 3. pp. 1563-1566. https://doi.org/10.1109/NSSMIC.2004.1462538.

Sumesh, C.G., Vinod Kumar, A., Tripathi, R.M., Puranik, V.D., 2013. Comparison study and thoron interference test of different radon monitors. Radiat. Prot. Dosim. 153 (3), 309-315. https://doi.org/10.1093/rpd/ncs118.

Tokonami, S., Kovacs, T., Sugino, M., Kavasi, N., Takahashi, H., Kobayashi, Y., Sorimachi, A., Ishikawa, T., Yoshinaga, S., 2008. Influence of environmental thoron on radon measurements and related issues. In: AIP Conference Proceedings, . https://doi.org/ $10.1063 / 1.2991193$.

Tommasino, L., 2001. Personal dosimetry and area monitoring for neutrons and radon in workplaces. In: Radiation Measurements, . https://doi.org/10.1016/S13504487(01)00205-0.

Tripathi, R.M., Sumesh, C.G., Vinod Kumar, A., Puranik, V.D., 2012. Application of thoron interference as a tool for simultaneous measurement of radon and thoron with a pulse ionisation chamber. Radiat. Prot. Dosim. 155, 155-160. https://doi.org/10. 1093/rpd/ncs324.

Venoso, G., Ampollini, M., Antignani, S., Carpentieri, C., Bochicchio, F., 2016. In-field evaluation of the impact of ageing and fading effects on annual radon concentration measurements for two different techniques. J. Radiol. Prot. 36 (4). https://doi.org/ 10.1088/0952-4746/36/4/922.

World Health Organization, 2009. WHO handbook on indoor radon a public Health perspective. Int. J. Environ. Stud. https://doi.org/10.1080/00207230903556771. 